\title{
LATINOAMÉRICA EN LA HISTORIA DE LA ARQUITECTURA MODERNA
}

Victoria Fernández

María José Palomino 


\section{VICTORIA FERNÁNDEZ}

Arquitecta. Facultad de Arquitectura, Universidad ORT Uruguay. Arquitecta en DA Arquitectura. Actividad profesional independiente.

\section{MARÍA JOSÉ PALOMINO}

Arquitecta. Facultad de Arquitectura, Universidad ORT Uruguay. Arquitecta en González Cano arquitectos. Actividad profesional independiente.

FECHA DE RECEPCIÓN: 5 de junio de 2018

FECHA DE ACEPTACIÓN: 20 de julio de 2018.

REGISTRO BIBLIOGRÁFICO: Fernández, F., \& Palomino, M. (2017). Latinoamérica en la historia de la arquitectura moderna. Anales de Investigación en Arquitectura, 7, 45-68. 


\section{RESUMEN}

El presente artículo se propone analizar el lugar de Latinoamérica en la historiografía de la arquitectura moderna y su evolución a través del tiempo. Los pioneros historiadores que abordaron esta temática construyeron la idea de un movimiento de características universales, que partió en realidad de la consideración de un limitado sector geográfico. Pero progresivamente se hizo más difícil darle la espalda a esta región del mundo cuya arquitectura moderna comenzaba a destacar tanto cualitativa como cuantitativamente. De manera selectiva e inexacta comenzó a inmiscuirse esta región en una producción historiográfica cuyo origen era principalmente europeo y norteamericano.

El lugar de América Latina en estas historias creció de manera relevante, después de evidenciada la crisis de la arquitectura moderna como la habían concebido los pioneros. Desde el propio ámbito latinoamericano comenzó a desarrollarse una historiografía que se propuso comprender su arquitectura a partir de la consideración de las particularidades locales y en el ámbito internacional se realizaron revisiones de las historias oficiales que progresivamente fueron mitigando la sesgada mirada centro- periferia bajo la que se había considerado hasta entonces la arquitectura de la región.

Palabras clave: Historiografía, Arquitectura Moderna, Latinoamérica

\section{ABSTRACT}

The present article intends to analyze the place of Latin America in the historiography of modern architecture and its evolution through time. The pioneering historians who approached this topic built the idea of a movement of universal characteristics that started from the consideration of a limited geographical area. But progressively it became more difficult to turn its back on this region of the world where modern architecture began to stand out both qualitatively and quantitatively. Selectively and inaccurately, this region began to interfere in a historiographic production whose origin was mainly European and North American.

The place of Latin America in these stories grew significantly, after evidencing the crisis of modern architecture as the pioneers had conceived it. From the Latin American area itself, a historiography began to be developed that aimed to understand its architecture from the consideration of local particularities, and in the international scope reviews were made of official histories that progressively mitigated the biased center-periphery view, under which until then the architecture of the region had been considered.

Key words: Historigraphy, Modern Architecture, Latin America. 


\section{HISTORIA, TIEMPO Y LUGAR}

La historia como ciencia no reproduce con total fidelidad el pasado, cada relato es el producto del trabajo interpretativo de un historiador, quien propone a partir de un recorte de los acontecimientos una mirada posible pero no única de la realidad. Tanto el momento histórico como el contexto cultural en el que vive desempeñan un papel importante en este recorte del pasado. Los intereses, prejuicios, proyectos, preocupaciones y metodologías disponibles del presente, que lejos de ser universales, responden en muchos casos a líneas de pensamiento determinadas geográficamente, influencian la interpretación. La historiografía de la arquitectura moderna, comenzó a construirse en paralelo a las obras y las teorías que estudiaba, por ello ha sufrido con el pasar del tiempo una continua actualización. Como sostiene Tournikiotis (2001) existen sobre esta temática una pluralidad de historias igualmente posibles que relatan los mismos acontecimientos de maneras distintas, tornando a la arquitectura moderna en un fenómeno complejo y heterogéneo desde el punto de vista histórico.

Mientras los movimientos de vanguardia que surgieron en Europa a comienzos del siglo XX como reacción a la arquitectura de los revivals buscaban crear obras adecuadas a la modernidad rechazando a la historia y a la arquitectura del pasado como fuentes del diseño arquitectónico contemporáneo
(Gutiérrez y Gutiérrez Viñuales, 2012); la arquitectura latinoamericana se encontraba por entonces embarcada en una búsqueda diferente. Más que construir una arquitectura adecuada a la época el objetivo era encontrar un estilo latinoamericano, adecuado al lugar, que lograra sobreponerse a los estilos europeos que carecían de consideración hacia el pasado y las características de América Latina. (Gutiérrez, 1985) Como sostiene Ainsa (1999) en el intento de proyectarla hacia el futuro, la región adquiere desde su incorporación al mundo occidental la condición de un lugar vacío y sin historia, lo que ha propiciado la importación de modelos extranjeros, que no consideran las particularidades y las preexistencias del subcontinente. Pero la negación de su historia ha teñido a Latinoamérica de nostalgia (Ainsa, 1999), por ese pasado perdido, cuya recuperación es fundamental para construir una historia propia, comprender su presente y determinar el camino a recorrer. Como sostiene Gutiérrez (1985), el modelo europeo con el que la región había buscado identificarse, sufre con la Primera Guerra Mundial y la Revolución Rusa una crisis a comienzos del siglo XX, época en la que se produjeron en Latinoamérica importantes cambios a nivel político, social e intelectual, que impulsaron la reflexión identitaria, la construcción de una historia y una cultura que naciera de la región. (Zea, 1978) En el ámbito arquitectónico el intento de encontrar un estilo propio, se vio reflejado en la recuperación de la arquitectura indígena y colonial que de acuerdo a las particularidades históricas de cada país 
se incorporaron en sus versiones "neo", como estilos propios, reflejo de las verdaderas raíces del subcontinente. (Gutiérrez, 1997)

\section{El desarrollo historiográfico sobre la arquitectura} en ambas regiones del mundo, se alineó rápidamente a estos cambios en la práctica de la disciplina. Esto derivó en relatos involucrados que superando su condición de historiografía se tornaron operativos, proyectando su idea de arquitectura hacia el futuro y señalando más o menos explícitamente- el camino que esta debía recorrer. Mientras en Latinoamérica los estudios históricos sobre la arquitectura tomaron en las primeras décadas del siglo XX un rol protagónico en la búsqueda de una arquitectura con raíces propias; en Europa y en Norteamérica, comenzó a construirse en la década del 30 la historiografía de la arquitectura moderna, pasando por alto su declarado rechazo hacia el pasado. Por un lado, estos primeros abordajes históricos sobre el tema lograron justificar la ruptura antihistoricista de las vanguardias, marcando el final del "período de sospechas con respecto al conocimiento histórico en sí mismo". (Tournikiotis, 2001, p. 224) Pero por otro lado, este logro fue a costa de "aquello que más temían los propios arquitectos modernos: su historización”. (Vidler, 2011, p. 24).

La necesidad de emprender la búsqueda de una arquitectura adecuada a la época, alcanzó en los albores de la década del 30 al subcontinente latinoamericano, no en perjuicio de la búsqueda de una expresión arquitectónica que partiera de la consideración de las particularidades de la región. Sin embargo, a diferencia de la relación que mantuvo la historiografía con el desarrollo de la arquitectura moderna en el hemisferio norte, aquí como plantea Gutiérrez (1985) desde mediados de la década de 1930 y hasta fines de los años 60, la arquitectura colonial y prehispánica continuaron siendo los temas centrales del estudio historiográfico. El operativismo ideológico y militante que lo había caracterizado las décadas previas fue dejado de lado, recluyéndose dentro de un ámbito académico y logrando lo que los europeos y norteamericanos no consiguieron, posicionarse ahistóricamente frente a la arquitectura moderna de la región.

Mientras desde Latinoamérica se negaba el abordaje historiográfico de esta temática, se construyeron dentro de una concentrada distribución geográfica muchas de las historias más difundidas de la arquitectura moderna. Esto redundó en la parcialidad de los discursos, que centrados en los intereses, prejuicios, proyectos, preocupaciones y metodologías de los lugares donde se construyeron, fundaron la idea de una arquitectura moderna que se vio reducida a la propiedad de un sector del mundo. Estas historias posicionaron a Europa y a Estados Unidos como los lugares centrales del desarrollo de la arquitectura moderna, mostrando muchas veces al resto del planeta, incluyendo a Latinoamérica, como zonas periféricas, incluso no dignas de ser incluidas 


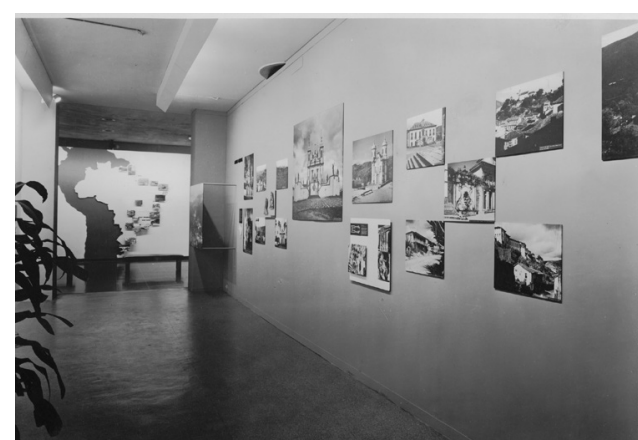

Figura 01.

Exposición Brazil Builds, MoMA, Nueva York, 1943. en la historia. Como señala Shmidt (2012) la caracterización de "América Latina, como parte de un Tercer Mundo situado -según la teoría de la dependencia- en la periferia (...) está en la base de la construcción de las historias de la arquitectura (...) desde la perspectiva geocultural." (p. 323)

\section{AUSENCIAS E INCORPORACIONES EN LA CONSTRUCCIÓN DE UN MOVIMIENTO}

Ninguna de los pioneros historiadores que emprendieron la construcción de la historiografía de la arquitectura moderna, el norteamericano Henry-Russel Hitchcock quien escribió Modern Architecture, Romanticism and Reintegration (1929) y The International Style (1932) junto a Philip Johnson, el alemán Nikolaus Pevsner con Pioneros del Diseño Moderno: de William Morris a Walter Gropius (1936) y el suizo Sigfried Giedion con Espacio, Tiempo y Arquitectura: origen y desarrollo de una nueva tradición (1941); incluyó en una primera edición mención alguna sobre la arquitectura de América Latina. Estos historiadores construyeron genealogías optimistas y sin fisuras mostrando una arquitectura moderna homogénea y universal, condicionando la elección de episodios, arquitectos y obras. Incluso El estilo Internacional (1932) que apelaba al carácter internacional de la nueva arquitectura, incluyó obras y arquitectos de limitadas regiones del mundo, dejando esta por fuera. Esteban Maluenda (2016) sostiene que la ignorancia de los primeros historiadores 
sobre la región parecía ser casi total, y si por el contrario se encontraban informados, lo que descubrieron no les pareció digno de mayor mención.

A partir de la segunda posguerra se construyeron nuevas historias de carácter retrospectivo, que tomando estos textos pioneros como punto de partida, propusieron su revalorización. Por entonces la historiografía de la arquitectura moderna llevaba ya una década de desarrollo sin incluir la producción latinoamericana, pero esta ya había comenzado a alcanzar reconocimiento en el ámbito internacional. Arquitectos de otras latitudes pudieron ver de primera mano su producción arquitectónica y los latinoamericanos demostraron fuera el nivel alcanzado en la obra y la crítica. Un episodio significativo en esta difusión, que evidenció el tipo, calidad y cantidad de arquitectura moderna latinoamericana fue la exposición Brazil Builds realizada en 1943 por el MoMA. A través de una mirada entusiasta, el catálogo de la exposición contó sobre una arquitectura que, si bien era resultado de la expansión del movimiento a todas partes del mundo, se había desarrollado de forma especialmente innovadora, impulsando el reconocimiento de la arquitectura moderna brasileña a nivel mundial, que comenzó a aparecer en revistas especializadas de países como Inglaterra, Francia y Estados Unidos. (Hitchcock, 1955, p.12)

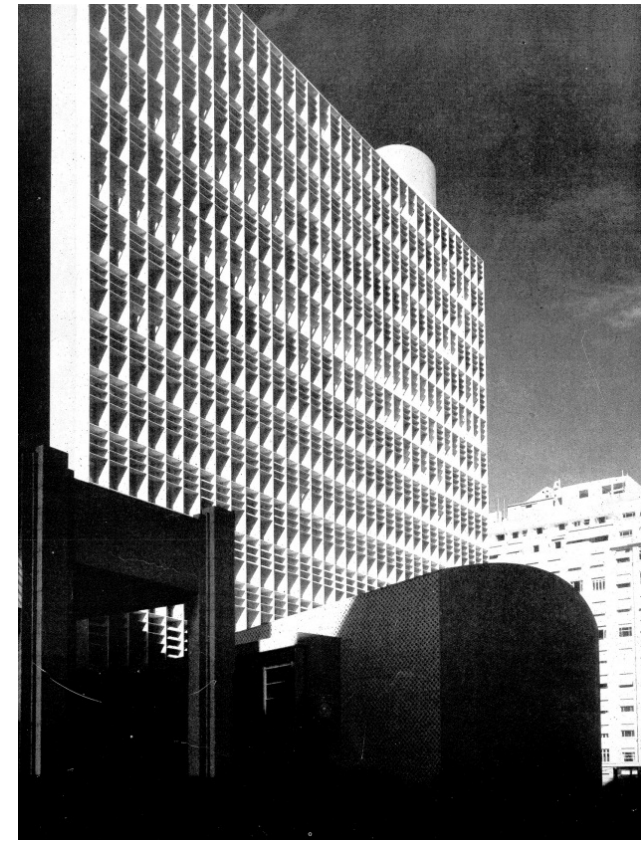

Figura 02.

Foto del Ministerio de Educación y Salud publicada en 1944 en The Architectural Review. 


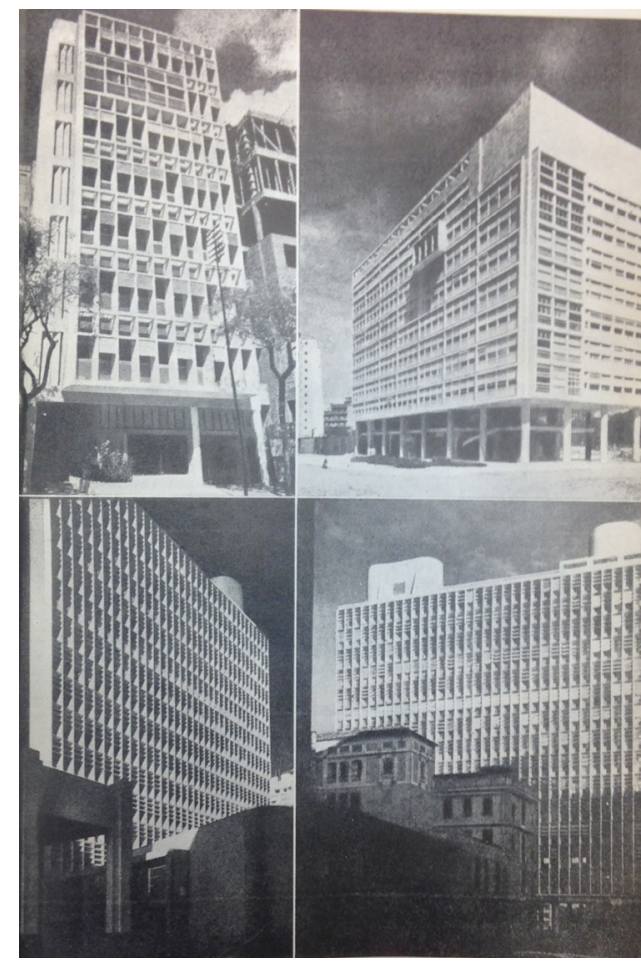

Figura 03.

Fotos del departamento para arquitectos, Edificio IRB y Ministerio de Educación y Salud, en Zevi (1954).

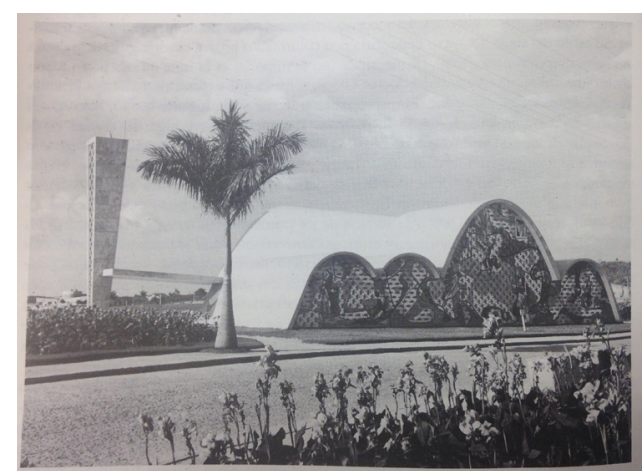

Figura 04.

Foto de la Iglesia de Pampulha en Pevsner (1994).
Sin embargo, esta difusión no se vio mayormente reflejada en los nuevos relatos historiográficos en los que, si bien la exposición pudo haber influido en la predominancia de las apariciones brasileñas en comparación con la producción arquitectónica del resto de la región, se estuvo lejos de mostrar una imagen completa de su arquitectura. Pero mucho más lejos se estuvo de lograr un entendimiento de la arquitectura moderna latinoamericana en su conjunto. El italiano Zevi en su Historia de la arquitectura moderna (1950) fue el primero que hizo mención a esta región del mundo en una primera edición, sin embargo, esta resulta realmente mínima, al igual que la que realiza Pevsner siete años después en la quinta edición (1957) del libro Breve historia de la arquitectura europea. Resulta sorprendente, como ambos autores construyen imágenes considerablemente distintas de la arquitectura latinoamericana. Mientras que Zevi muestra como esta sigue los lineamientos internacionales del racionalismo moderno provenientes de Europa y Estados Unidos, Pevsner destaca obras cuyas formas considera se alejan de la simpleza geométrica, resultando irracionales y exuberantes, e implicando incluso el riesgo de corromper el modernismo occidental. (Del Real, 2015)

Estasprimerasincorporacionesextremadamente selectivas, incluyen únicamente aquellas obras 0 arquitectos de la región que funcionan dentro de la genealogía que proponen, planteando una visión simplificada de la misma que está lejos de mostrar y comprender su diversidad. No 
solo porque no consideran una diversidad de países -ambos hacen referencia de manera predominante al caso brasileño-, sino también porque a partir de la arquitectura que muestran crean una visión generalizadora que propicia la malinterpretación de la arquitectura de la región.

Fue Hitchcock quien con motivo de la exposición del MoMA Latin American Architecture since 1945 y su catálogo realizados en 1955, se convirtió en el primero de estos historiadores extranjeros en conocer de primera mano la arquitectura de estas latitudes. Esta segunda exposición del museo implicó en comparación con la primera un cambio importante. Al incluir 11 países abarcó por primera vez un amplio espectro de la arquitectura del subcontinente, superando la idea de que las experiencias significativas se encontraban acotadas solamente a la producción de escasos países. Si bien no se incluyó a América Latina dentro de un relato global de la arquitectura moderna, se inauguró el capítulo de las historias que abordan el estudio específico del desarrollo de esta arquitectura en la región, que más tarde continuarían principalmente los propios latinoamericanos.

El catálogo de Hitchcock (1955) parte una mirada extranjera, y muestra la arquitectura moderna latinoamericana desde la perspectiva de la dependencia cultural. La influencia europea y norteamericana son consideradas el punto de partida, a partir del que la región 
logra desarrollar experiencias relevantes tanto en cantidad como en calidad, pero sin lograr “experiencias autóctonas importantes" (p. 17). Esta exposición y su catálogo generaron una gran repercusión en el ámbito internacional, ubicando al continente en un lugar protagónico del debate arquitectónico. Del Real (2015) sostiene que este estudio, al igual que otros que por esos años trataron particularmente el caso latinoamericano tuvieron a pesar de su difusión y entusiasmo poco impacto en las historias posteriores.

No cabe duda que al historiador que más influyó el estudio patrocinado por el MoMA fue al propio Hitchcock, quien en 1958 publicó una nueva historia titulada Arquitectura de los siglos XIX y XX. La cercanía temporal entre este libro y la experiencia del autor en Latinoamérica, fue determinante en la importancia que se le otorga a la región en la primera edición, incorporando experiencias de 9 países, la mayoría de los cuales encontraban por primera vez su lugar dentro de una mirada global del movimiento. Pero esta importancia, como estudia Del Real (2011) en su ensayo Para caer en el olvido: Henry-Russell Hitchcock y la arquitectura latinoamericana, fue disminuyendo sucesivamente en las siguientes ediciones de la historia.

Las historias publicadas a principios de los años sesenta no abrazaron el entusiasmo inicial de Hitchcock por la arquitectura de gran parte de los países latinoamericanos, las menciones que estos difundidos libros de la historia de la arquitectura moderna como La Historia del movimiento moderno del italiano Benevolo publicada por primera vez en 1960 o las nuevas ediciones de la historia de Giedion hicieron sobre la región, le otorgaron nuevamente a Brasil el lugar protagónico y dejaron en algunos casos por fuera a todo el resto del subcontinente. La experiencia de la nueva capital brasileña, cuya construcción comenzó en 1956, generó gran atención en el ámbito internacional y fue incorporada dentro de las historias incluso en forma simultánea a su construcción, robándole importancia al resto de la arquitectura de este país que quedó en algunos casos bajo la sombra del pájaro de Brasilia.

La Historia de Benevolo incluye en su primera edición un espacio dedicado a Brasil que como abanderado representó la arquitectura de la región, dentro de un capítulo que trata experiencias de la arquitectura moderna periféricas. A pesar de esta condición, Benevolo (1999) valoriza estas experiencias y reconoce la importancia que han comenzado a adquirir a nivel internacional, así como el grado de independencia que han alcanzado, proponiendo una mirada distinta en comparación con las historias previas, reconociendo su positiva autonomía y señalando su capacidad de influir en las regiones centrales. La experiencia a la que presta mayor atención, es al proyecto para la nueva capital brasileña, que como señala Del Real (2015) significó para el autor un experimento único para el Movimiento Moderno 
que implicaba un importante giro en la geografía del modernismo. Como sostiene Esteban Maluenda (2016) en la primera edición del libro, debido a la incertidumbre que la reciente inauguración de la capital -también en 1960generaba sobre sus resultados a nivel urbano, Benevolo no se arriesgó a declarar su opinión al respecto de la experiencia, cuyo efecto quedó plasmado en posteriores ediciones, cuando la nueva capital se cuestionaba a nivel mundial y el autor plantea su postura cargada de negatividad, sentenciando con este proyecto el final de una etapa próspera para la arquitectura, no solo de este país sino de toda Latinoamérica.

Esta nueva capital ocupó también un lugar significativo entre las tímidas menciones latinoamericanas incorporadas en las nuevas ediciones de la historia de Giedion. A partir de la cuarta (1962) el autor agrega una introducción donde trata el estado de la arquitectura contemporánea. El autor establece ser consciente de que la arquitectura moderna se ha expandido y no pueda ya ser entendida únicamente a partir de la experiencia de una acotada región del mundo. Reconoce en este sentido la existencia de dos dimensiones en el desarrollo de la arquitectura, una basada en las características arquitectónicas arraigadas a la cultura local, y otra basada en la expresión y concepción espacial moderna. La nueva arquitectura no se entiende ya como internacional, sino que el diálogo entre estas dos dimensiones propicia el desarrollo de obras que, bajo las mismas ideas universales,
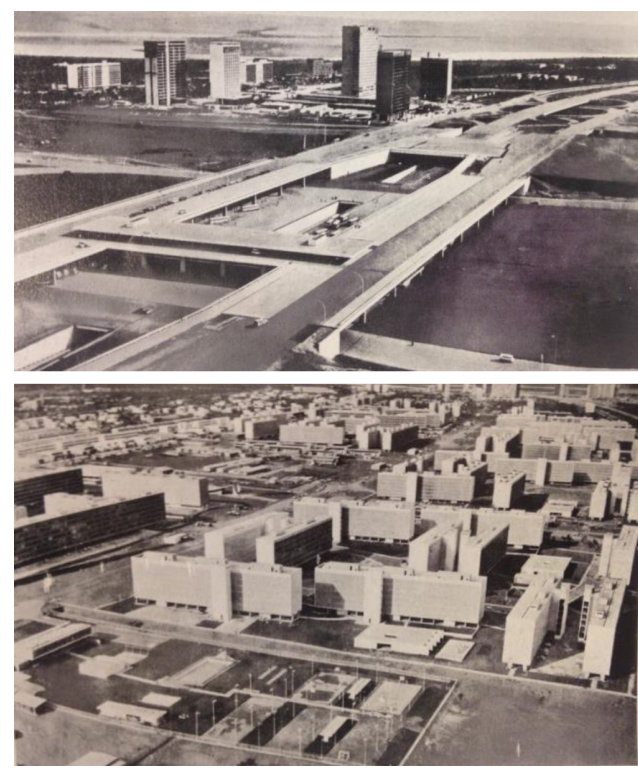

Figura 07 y 08.

Fotos de Brasilia en Benevolo, (1999). 
resultan polifónicas. A pesar de otorgarle a esta idea carácter global, el historiador se refiere en su prefacio a unos pocos países periféricos, que representan para él la concreción más satisfactoria de esta dialéctica, entre los cuales de Latinoamérica se centra nuevamente en Brasil y concretamente en su nueva capital, planteando una mirada positiva tanto de su arquitectura como de su urbanismo.

Durante las poco más de tres décadas que separan la primera historia de la arquitectura moderna de Hitchcock (1929) de la cuarta edición de la historia de Giedion (1962), los relatos presentados narran la historia partiendo del optimismo, comprometidos con el éxito de la nueva arquitectura. Sin embargo, estas historias realizan planteos que evidencian el transcurrir del tiempo y de la práctica arquitectónica, lo que se ve también reflejado en la incorporación latinoamericana. Mientras que las primeras historias construyeron el mito de una arquitectura moderna universal a partir de la consideración de un limitado sector geográfico que no incluyó a Latinoamérica, las historias publicadas en la segunda posguerra comenzaron a evidenciar el carácter no tan uniforme y homogéneo de la nueva arquitectura e incorporan las primeras menciones a esta región. Se incluyen aquellas experiencias que desde el ámbito internacional habían resultado más llamativas y que podían incorporarse al relato sin alterar la idea que pretendía construir el historiador. Esto redundó en una muestra muy escasa y parcial de arquitectos y obras, en la mayoría de los casos brasileños. Sin embargo, a pesar de lo acotado de estas menciones, las historias de Benevolo (1960) y Giedion (1962) de la década del 60 presentan un cambio conceptual significativo. Mientras Benevolo reconoce el autónomo desarrollo de la arquitectura de la región, Giedion reflexiona que la arquitectura no debe responder únicamente a un tiempo sino también al lugar donde se desarrolla, evidenciando ambas posturas el cuestionamiento que ya por entonces se encontraba establecido de la existencia de una arquitectura moderna de características universales.

\section{REFLEXIONES PROPIAS Y REVISIÓN AJENA DESDE LA CRISIS}

La historia del inglés Banham Teoría y diseño arquitectónico en la era de la máquina, publicada en 1960 al igual que la historia de Benevolo inauguran la mirada crítica sobre la arquitectura moderna. Por primera vez la imagen que la historia ayudó a idealizar, no resulta del todo adecuados ni suficiente. Para la década de 1960 el sentimiento esperanzador y la certeza futura que había acompañado a la arquitectura moderna en su comienzo, había comenzado a evaporarse, su lugar lo ocupaba ahora la incertidumbre sobre el camino futuro de la disciplina. Se hablaba de un momento de crisis, los postulados e ideales anteriores comenzaron a revisarse y reinterpretase con el objetivo de comprender dónde estaban las omisiones y los equívocos que habían ocasionado el devenir 
de la situación contemporánea. La historia no logró escapar a esta revisión y fue escrita nuevamente, desde la perspectiva del nuevo presente.

La revisión crítica de la arquitectura moderna se extiende durante la década del sesenta, ya no es posible ignorar la complejidad, multiplicidad y heterogeneidad de la arquitectura contemporánea. La historia del inglés Collins Los ideales de la arquitectura moderna; su evolución (1750-1950) publicada en 1965, al igual que la ya mencionada historia de Banham, proponen relatos alternativos, mientras que el italiano Tafuri en Teorías e Historia de la Arquitectura (1968) alcanza el punto más alto y radical dentro de esta crítica. Este autor no solo pretende quebrar la imagen erguida por las historias anteriores, sino que se dirige a la raíz y cuestiona el hecho de historiar la arquitectura moderna, concluyendo que el antihistoricismo propuesto por las vanguardias era en realidad la legítima respuesta histórica. Tournikiotis (2001) sostiene que esta historia cierra el ciclo de las historias activas de la arquitectura moderna -dentro de la historia oficial- las que representaron el auge de la relación entre la historia y la práctica arquitectónica (Fernández, 2004). Al producirse el retorno a su escritura será desde una mayor distancia, que permitirá interpretar de forma más objetiva y conciliadora la temática, sin interés operativo alguno.

Estas nuevas historias no significaron una mejoría desde el punto de vista de la inclusión latinoamericana en comparación con aquellos relatos que buscaban refutar. A pesar de proponerse mostrar los problemas, las fisuras, la diversidad y las inconsistencias dentro de la arquitectura moderna como construcción historiográfica, no intentaron cambiar la sesgada mirada centro- periferia ni enfrentar la simplificación geográfica que había derivado en la total ausencia latinoamericana en las primeras historias y en sus limitadas incorporaciones posteriores. Incluso Banham volvió a caer en la misma inconsistencia en la que habían caído Hitchcock y Johnson más de tres décadas antes, al llamar a la arquitectura moderna "estilo internacional", cuando en su historia no es posible percibir dicho carácter internacional. Esteban Maluenda (2016) plantea que suele relacionarse el desencanto que produjo la nueva capital brasileña con este retorno a la ausencia de América Latina. El interés en ella se transformó en rechazo, perdiendo su lugar en la mayoría de las historias y dejando un vacío latinoamericano. La completa ausencia de esta región en las historias no se produjo -como también señala Esteban Maluenda (2016)dentro de otros medios de difusión, donde el efecto Brasilia afecto a su país, pero no a todo el resto del subcontinente.

Es en el marco de esta crisis en la que Latinoamérica no parecía tener un lugar asignado, comienza a fines de la década del sesenta, en la región, el estudio historiográfico de la arquitectura moderna propia. Finalmente se aborda desde esta perspectiva el conflicto 
que tres décadas antes había quedado establecido, entre la idea de arquitectura moderna que habían construido las historias extranjeras y las voces que a principios del siglo XX ya habían proclamado en Latinoamérica la necesaria búsqueda de una historia y una cultura propia, la búsqueda de su identidad. Arango plantea en su artículo "Arquitectura moderna latinoamericana: El juego de las interpretaciones" (2012) que es posible interpretar la arquitectura latinoamericana de dos maneras opuestas. Por un lado, insertándose en un marco internacional, a partir de un análisis del estilo y la forma que como elementos que provienen de la influencia extranjera niegan la posibilidad de la región de construir obras con respuestas autóctonas. Mientras que por otro lado, puede realizarse un análisis desde las particularidades sociales, políticas y culturales de la región, que muestre el desarrollo de una arquitectura que surge como respuesta a la identidad local. El objeto estudiado es en ambos casos el mismo pero la interpretación varía al cambiar el lado desde el que se observa. Mientras el primero de estos criterios considera únicamente la arquitectura de estas latitudes en relación a una evolución temporal de carácter universal, sin considerar las particularidades del lugar, el segundo logra integrar ambos aspectos al analizar la adecues de la arquitectura para su tiempo y lugar.

Los trabajos historiográficos que hasta entonces sobre la arquitectura moderna se habían construido, habían considerado a Latinoamérica -cuando lo hicieron- a partir del primero de estos criterios. Incluso las exposiciones del MoMA y sus catálogos, que mostraron una amplia muestra de la arquitectura de la región, lo hicieron desde una mirada que no buscó reducir su distancia, mostrando el caso latinoamericano como un buen ejemplo de modelos importados nunca considerándolo desde sus particularidades. Pero, ¿cómo pretender que se reconozca con precisión estas particularidades regionales, si ni siquiera eran consideradas por los propios latinoamericanos dentro de su historia?

Mientras la historiografía "internacional" se debatía sobre los posibles caminos futuros de la arquitectura, Latinoamérica reconoció que no debía aceptar sin más los caminos desde afuera propuestos, era necesario entender su arquitectura en relación con la identidad local, para poder trazar un camino propio que respondiera a sus necesidades particulares. El estudio historiográfico sobre la arquitectura moderna en Latinoamérica surge como un esfuerzo individual a partir de las publicaciones realizadas por Bullrich en 1969 Arquitectura Latinoamericana, 1930-1970 y Nuevos Caminos de la Arquitectura Latinoamericana. Pero este se contagió rápidamente, alcanzando en las décadas posteriores un significativo número de publicaciones que crearon un diverso conjunto historiográfico, intrínsecamente latinoamericano, sobre la arquitectura moderna de la región. Estas historias, entre las que podemos encontrar las de Gutiérrez (1983), 
Browne (1988) y Segre (1991), se propusieron considerar la arquitectura moderna sin juzgarla bajo los parámetros de otras coordenadas.

Paralelamente al surgimiento de estas voces latinoamericanas, surgieron en el ámbito internacional nuevas historias, ampliamente difundidas, que desde una mirada más distante, se incorporaron a la historia oficial de la arquitectura moderna. Tal fue el caso de la Historia Crítica de la Arquitectura Moderna (1980) del inglés Frampton y de La Arquitectura Moderna desde 1900 (1982) de su compatriota Curtis. Incentivados tal vez por las primeras historias latinoamericanas que tuvieron difusión en el ámbito internacional, estos relatos retomaron la inclusión de América Latina después del vacío que dejó la historia al proclamar la crisis. Mientras Frampton, hace mención a estas latitudes con un alcance similar al presentado por Benevolo en su historia publicado dos décadas antes, Curtis si bien están lejos de proponer una cambio muy significativo, va un poco más allá, guiando el camino posterior. El aspecto más destacable de la primera edición de su historia resulta el lugar dedicado a la arquitectura mexicana, que ocupa un lugar de mayor importancia que el de la arquitectura carioca, el otro país de la región al que menciona. El arquitecto mexicano Luis Barragán quien había ganado el premio Pritzker en el año 1980, hace su primera aparición dentro de este conjunto historiográfico, tornando en el planteo de Curtis los orígenes de la arquitectura moderna latinoamericana, en unos más difusos que los presentados anteriormente, ya que mientras los brasileños asocian a la influencia europea, los del arquitecto mexicano resultan para Curtis mucho menos evidentes. (Esteban Maluenda, 2016)

Otro avance en la desestructuración de la mirada geográficamente sesgada, puede identificarse en la nueva edición en español publicada en 1982 del libro Historia de la arquitectura moderna de Benevolo que incorpora un nuevo capítulo, de autoría de Montaner titulado La arquitectura moderna latinoamericana. Si bien este capítulo identifica el comienzo de la arquitectura moderna latinoamericana con uno importado, hace énfasis en la continua búsqueda que en ella se ha hecho de una expresión propia, negando implícitamente la existencia de un lenguaje universal. EI principal aporte de este capítulo recae en el amplio espectro temporal en el que considera la arquitectura latinoamericana, alcanzando incluso la contemporaneidad del relato, así como en la incorporación de un número de países, obras y arquitectos que, aunque no tratados con profundidad, aparecen por primera vez dentro de esta historiografía, . Arquitectos de la importancia de Clorindo Testa, Amancio Williams, Mario Roberto Alvarez, Julio Vilamajó, Eladio Dieste, Ricardo Salmona y Carlos Raúl Villanueva, solo nombrando algunos de los tantos que integran la selección, aparecen mencionados por primera vez en una historia de este alcance y difusión, aunque resulta necesario aclarar que el capítulo funciona 


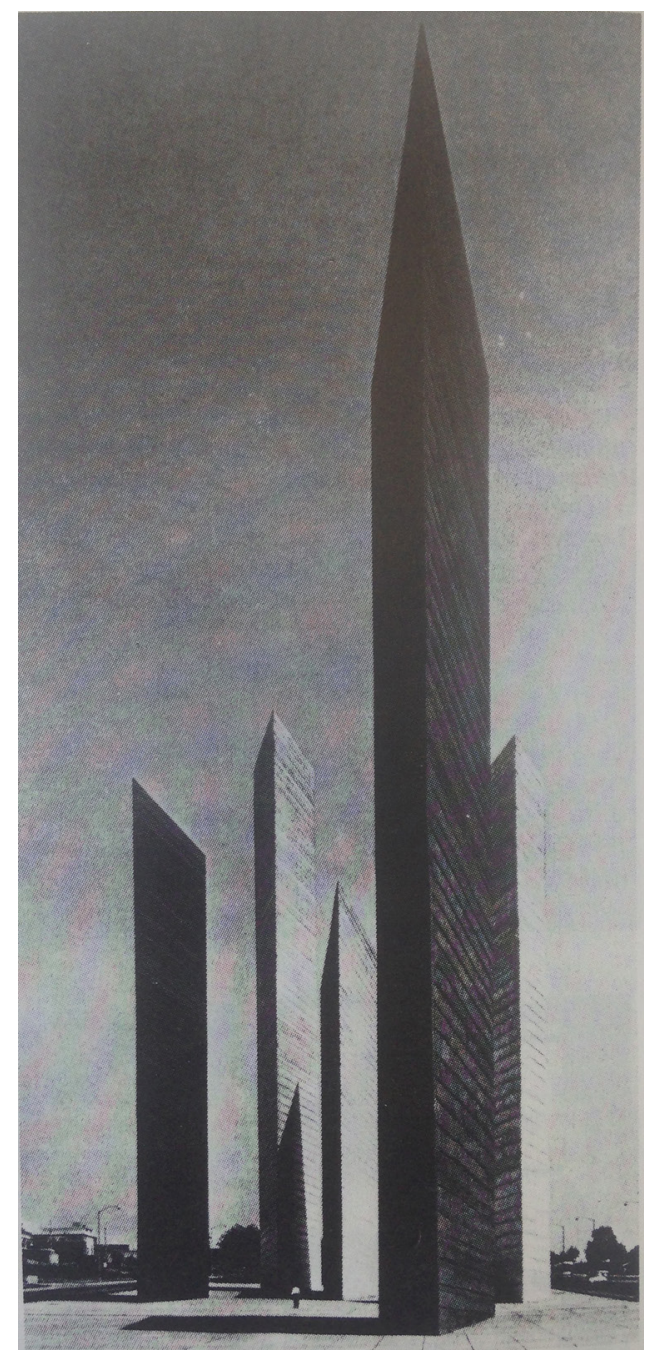

Figura 09

Torres de la Ciudad Satélite, de los arquitectos Barragán y Goeritz, Ciudad de México (1957) en Frampton (1993). como un anexo incorporado únicamente a las ediciones en castellano.

Otra revisión que en forma de nueva edición plantea novedades, es la segunda edición de la historia de Frampton (1983), en la que el historiador incorpora el ensayo en el que presenta al regionalismo crítico como categoría de análisis, a partir de la cual identifica en la obra de ciertos arquitectos modernos, cuyos trabajos se localizan en lugares periféricos, la inclusión de referencias culturales regionales. Como el autor aclara, se trata de una arquitectura capaz de asimilar las influencias ajenas, reinterpretándolas desde la cultura propia. Estas obras entre las que menciona ejemplos latinoamericanos, haciendo especial énfasis en la arquitectura de Barragán logran una síntesis entre lo local y lo internacional, planteando para Frampton, la posibilidad de mitigar la destrucción de las culturas regionales, producto del proceso de modernización y globalización. Constituye para él una actitud de resistencia, que presenta un posible camino frente a la crisis de la arquitectura moderna, uno que el historiador evalúa positivamente.

El planteo que realiza Frampton con el regionalismo crítico tuvo como sostiene Schmidt (2012) una repercusión significativa dentro del ámbito latinoamericano, ya que “paradójicamente, actúa como un cristalizador de la distancia de un tercer mundo, ahora revalorizado por sus dotes particulares y que no necesita alcanzar el primero". (p. 334) 
Sin embargo, desde la región autores como Fernández Cox (1991) y Waisman (1991) plantean su disconformidad con este planteo. Mientras el primero señala que la denominación regionalismo como variante local implica inevitablemente la dependencia de un centro, Waisman desconoce que estas particularidades locales impliquen una actitud de resistencia idea que considera hace referencia a "quedarse en el refugio mientras el mundo se derrumba. (...) < Nosotros> estamos más cerca de una vanguardia que de una retaguardia. Al menos, estamos marchando en lugar de permanecer". (1991, p. 93) Más allá de estas diferencias puede establecerse una posible interconexión y retroalimentación entre la importancia que empezó a cobrar la idea del regionalismo en la historiografía oficial de la arquitectura moderna y el gran incremento que en la década del 80 tuvo en la región el desarrollo de la historiografía propia.

La extensa revisión realizada por Curtis para la tercera edición de La arquitectura moderna desde 1900 significó también en esta historia un importante cambio en cuanto al lugar ocupado por Latinoamérica. La nueva edición aborda la arquitectura de varios países de la región en cuatro capítulos diferentes, ubicados en distintos lugares del libro. Pero incluso el considerable lugar que adquiere Latinoamérica en cada uno de ellos, no resulta como sostiene Esteban Maluenda (2016) lo más destacable de esta historia, como sí lo son las menciones a países y a arquitectos que Curtis naturalmente

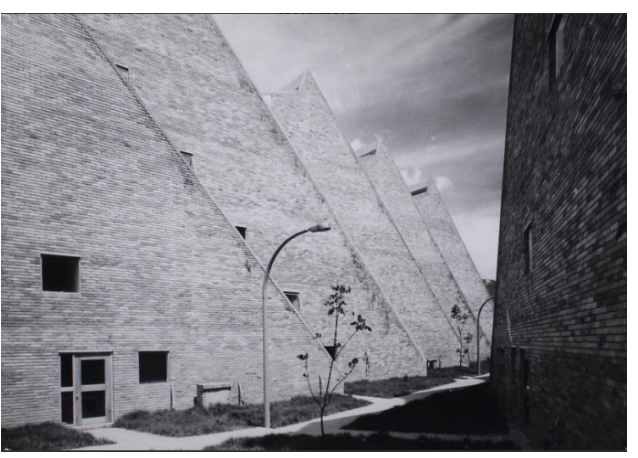

Figura 10.

Complejo de Vivienda Social en San Cristobal, Colombia, en Latin America in Construction, Architecture 1955-1980. 
incorpora a lo largo del relato en otros capítulos. Son estas menciones, las que logran integrar finalmente a la región dentro de su historia de la arquitectura moderna. Curtis (2006) declara sobre la razón de los cambios incorporados, reconociendo la parcialidad de las miradas anteriores:

Determinados 'escenarios' de los libros anteriores sobre arquitectura moderna ya no resultan adecuados. (...) Una historiografía basada en las inclinaciones culturales y las estructuras de poder de la zona del Atlántico norte no tiene justificación cuando se aborda la difusión a escala mundial de la arquitectura moderna en lugares como América Latina, Oriente Próximo o India. Aún queda mucho por hacer en cuanto a la mezcla y la colisión de los tipos 'universalizadores' con las tradiciones nacionales y regionales, un rasgo básico de la arquitectura moderna (...) desde su comienzo. (p. 10)

Otra de las revisiones que creemos digna de mención, es la que llevó a cabo el MoMA en 2015: Latin America in Construction, Architecture 1955-1980, una exposición en conmemoración a la realizada sesenta años atrás que incorporó material inédito y abordó la arquitectura de diez países latinoamericanos incluyendo obras de un importante número de arquitectos. A pesar de que esta segunda exposición resulta en cuanto a los años que abarca una continuación de la anterior, propone una mirada distinta, ya no de un extranjero que descubre su arquitectura como pudo haber sido Hitchcock, sino una mirada que surge del propio ámbito latinoamericano incorporando además de a Bergdoll y Del Real -quien es latinoamericano-, a dos curadores invitados Liernur y Díaz Comas.

Como plantea Bergdoll (2015), la exposición comienza en el momento en el que el optimismo inicial a nivel internacional por la arquitectura moderna latinoamericana empieza a extinguirse, abarcando un período muy conflictivo político y socialmente, el período del desarrollismo. De esta forma, deja atrás la etapa hasta entonces más incorporada dentro de la historiografía de la arquitectura moderna, y se embarca en este período sólo mencionado por Montaner, presentándolo como período importante del legado arquitectónico, ya que como declara Bergdoll (2015) continúa existiendo en el ámbito internacional cierta ignorancia sobre la arquitectura de la región.

Personalmente, me sorprendió que Latinoamérica haya sido sistemáticamente excluida de mi formación (...). La mayoría de los libros de historia en inglés le asignan un rol secundario a América Latina, me intrigaba saber si, en la posguerra, la región había sido un actor igualmente importante que Norteamérica y Europa en el desarrollo transatlántico. No simplemente un lugar donde los alumnos de Le Corbusier fueron a construir, sino un lugar donde se originaron ideas. (párr. 2) ${ }^{1}$

\footnotetext{
1 Traducción propia.
} 
Ramón Gutiérrez uno de los autores latinoamericanos que ha abordado el estudio histórico de la arquitectura de la región, sostenía en 1985 que la mayoría de las historias que tratan esta temática analizan las obras de la región a partir de modelos extranjeros y dentro de los parámetros de la historiografía de la arquitectura occidental, asumiendo cronologías y categorías de análisis de otros, interpretando su historia desde la base de la dependencia cultural y descartando experiencias valiosas para la comprensión de la cultura de América Latina. Si bien no puede negarse el avance que desde esa fecha hasta aquí ha tenido la historiografía de la arquitectura moderna en la consideración del caso latinoamericano, incentivado tanto por el trabajo historiográfico de la propia región como por la crisis a nivel internacional de la idea de una arquitectura moderna como fenómeno universal; la reflexión planteada por Bergdoll (2015) evidencia que aún hay un camino por recorrer. Esta última exposición del MoMA así como las historias que desde la región continuaron construyéndose después del cambio de siglo, como es el caso de las de Segawa (2005) y Arango (2012), comprueban que la investigación histórica sobre la arquitectura moderna latinoamericana aún no se encuentra agotada, continúa teniendo interés y es posible construir sobre ella nuevas miradas que puedan contribuir como parte de este conjunto historiográfico a su mejor entendimiento. 


\section{BIBLIOGRAFÍA}

AINSA, F. (1999). La reconstrucción de la utopía. Buenos Aires: Ediciones del Sol.

ARANGO, S. (2012). Arquitectura moderna latinoamericana: El juego de las interpretaciones. (Universidad Nacional de Colombia). Accedido el 2 de Junio, 2018, desde https:// es.scribd.com/document/363952766/Silvia-Arango-Arquitetura-America-Latina

BANHAM, R. (1960). Teoría y diseño en la primera era de la máquina. Buenos Aires: Ediciones Nueva Visión SAIC.

BENEVOLO, L. (1999). Historia de la arquitectura moderna. Barcelona: G. Gili.

BERGDOLL, B., DIAS COMAS, C. E., LIERNUR, F. \& DEL REAL, P. (2015). Latin America in construction: Architecture 1955-1980. New York: MoMa.

BERGDOLL, B. (2015). The Future was Latin American: Barry Bergdoll on the region's Legacy of Visionary Modern Architcture, Metropolis. Accedido el 23 de Marzo, 2017, desde https://www.metropolismag.com/architecture/ moma-curator-barry-bergdoll-regions-rich-legacy-visionary-modern-architecture/

BULLRICH, F. (1969a). Arquitectura latinoamericana, 1930-1970. Buenos Aires: Sudamericana.

COLLINS, P. (1998). Los ideales de la arquitectura moderna; su evolución. Barcelona: G. Gili.

CURTIS, W. (2006). La arquitectura moderna desde 1900. Londres: Phaidon.
DEL REAL, P. (2011). Para caer en el olvido: Henry- Russell Hitchcock y la arquitectura latinoamericana, Block, (8), Universidad Torcuato Di Tella, Buenos Aires. 48-57.

DEL REAL, P. (2015). Bibliography, Museum of Modern Art. Accedido el día 5 de Febrero, 2017 desde https://www.moma.org/momaorg/shared/pdfs/docs/calendar/laa_bibliography.pdf

ESTEBAN MALUENDA, A. (2016). La arquitectura moderna en Latinoamérica. Antología de autores, obras y textos. Barcelona: Reverté.

FERNÁNDEZ COX, C. (1991). Modernidad apropiada. Modernidad revisada. Modernidad Reencantada, en Modernidad y Postmodernidad en América Latina. Estado del debate, (99-109), Bogotá: Escala.

FERNÁNDEZ, R. (2004). Construcciones históricas. Argumentos sobre el estado del conocimiento histórico de la arquitectura. Montevideo: FARQ.

FRAMPTON, K. (1983). Historia crítica de la arquitectura moderna. México: G. Gili.

GIEDION, S. (1961). Espacio, tiempo y arquitectura. El futuro de una nueva tradición. BarceIona: Científico-Médica.

GUTIÉRREZ, R. (1985). La historiografía de la arquitectura americana. Entre el desconcierto y la dependencia cultural (1870/1985), Summa, (215/216). Agosto. 40-59. 
GUTIÉRREZ, R. (1987). "Reflexiones para una historia propia de la arquitectura americana", Anales IAA, (25). 12-31.

GUTIÉRREZ, R. (1997). Arquitectura y urbanismo en Iberoamérica. Madrid: Ediciones Cátedra.

GUTIÉRREZ, R. \& GUTIÉRREZ VIÑUALES, R. (2012). Una mirada crítica a la arquitectura latinoamericana del siglo XX. De las realidades a los desafíos. En: Karge, Enrik (ed.). 18101910-2010. Independencias dependientes. Art and national identities in Latin America. Dresde, Universidad de Dresde. Accedido el día 11 de Diciembre, 2016, desde http:// www.ugr.es/ rgutierr/PDF1/171.pdf

HITCHCOCK, H. R. (1955). Latin American architecture since 1945. New York: MoMA.

HITCHCOCK, H. R.; JOHNSON, P. (1995). The International Style. New York: W. W. Norton.

PEVSNER, N. (1994). Breve historia de la arquitectura europea. Madrid: Alianza Editoriales.

SHMIDT, C. (2012). Las "Américas Latinas": intervenciones desde la historiografía de la arquitectura. En RIGOTTI A. M. \& PAMPINELLA S. (Eds.). Entre puntos cardinales. Debates sobre una nueva arquitectura (1920-1950). (321-336), Rosario: Prohistoria Ediciones.

TAFURI, M. (1997). Teorías e historia de la arquitectura. Madrid Celeste.

TOURNIKIOTIS, P. (2001). La historiografía de la arquitectura moderna. Madrid: Taschen.
VIDLER, A. (2011). Historias del presente inmediato. La invención del Movimiento Moderno arquitectónico. Barcelona: G. Gili.

WAISMAN, M. (1991). Un proyecto de modernidad, en Modernidad y Postmodernidad en América Latina. Estado del debate, (89-98). Bogotá: Escala.

ZEA, L. (1978). Filosofía de la historia americana. México: Fondo de Cultura Económica. Accedido el día 28 de febrero, 2017, desde http:// www.cecs-argentina.org/web2015/wp-content/uploads/2015/06/Zea-Leopoldo-Filosofia-de-la-historia-americana.pdf

ZEVI, B. (1954). Historia de la arquitectura moderna. Buenos Aires: Emencé. 


\section{FUENTE DE IMÁGENES}

Figura 01. Recuperada de: http://www.uncubemagazine.com/blog/15798317

Figura 02. Recuperada de: https://www.architectural-review.com/essays/archive/march1944-the-brazilian-style/8607496.article

Figura 03. Extraída de: ZEVI, B. (1954). Historia de la arquitectura moderna. Buenos Aires: Emencé.

Figura 04. Extraída de: PEVSNER, N. (1994). Breve historia de la arquitectura europea. Madrid: Alianza Editoriales.

Figuras 05 y 06. Recuperadas de: http://www. uncubemagazine.com/blog/15798317

Figuras 07 y 08. Extraída de: BENEVOLO, L. (1999). Historia de la arquitectura moderna. Barcelona: G. Gili.

Figura 09. Extraída de: FRAMPTON, K. (1993). Historia crítica de la arquitectura moderna. Barcelona: G. Gili.

Figura 10. Recuperada de: http://www.uncubemagazine.com/blog/15798317 